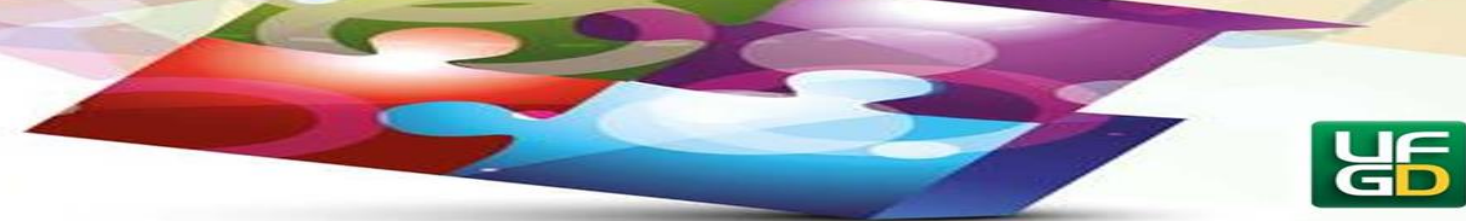

\title{
ATIVIDADE DE SITUAÇÕES PROBLEMA COMO ESTRATÉGIA DIDÁTICA NO TRATAMENTO DA INFORMAÇÃO EM UNIDADES DE MEDIDA DE TEMPO
}

\author{
ACTIVIDAD DE SITUACIONES PROBLEMÁTICAS COMO ESTRATEGIA \\ DIDÁCTICA EN EL TRATAMIENTO DE LA INFORMACIÓN EN UNIDADES DE \\ MEDIDA DE TIEMPO
}

Soraya de Araújo FEITOSA ${ }^{1}$

Rozenilda de SOUZA ${ }^{2}$

Oscar Tintorer DELGADO ${ }^{3}$

\begin{abstract}
Resumo: este artigo apresenta $2^{\mathrm{a}}$ fase de planejamento didático desenvolvido no âmbito do Mestrado Profissional em Ensino de Ciências da Universidade Estadual de Roraima e teve como sujeitos alunos do $6^{\circ}$ ano do Ensino Fundamental da Escola Estadual Professora Conceição da Costa e Silva, localizada em Boa Vista-RR. A investigação teve como objetivo geral estudar a aprendizagem dos alunos apoiando-se na base científico-psicológica da Teoria de Galperin. O planejamento didático contemplou a Atividade de Situações Problema no Tratamento da Informação (ASPTI) que, juntamente com a Teoria de Galperin, deram suporte à organização do plano de ações, à planilha de observação e à sequência didática. O estudo converteu-se em pesquisa-ação estratégica de abordagem qualitativa. Nos resultados observouse o desenvolvimento de habilidades e competências e melhor desempenho discente nas ações e operações da ASPTI em Unidades de Medida de Tempo.
\end{abstract}

Palavras-chave: Aprendizagem. Teoria de Galperin. ASPTI.

Resumen: este artículo presenta la $2^{\mathrm{a}}$ fase de la planificación didáctica desarrollada en el ámbito de la maestría en enseñanza de la ciencia de la Universidad Estatal de Roraima y tuvo como sujetos estudiantes del $6^{\circ}$ año de la Escuela Estadual Professora Conceição da Costa e Silva, ubicado en Boa Vista-RR. La investigación tuvo como el objetivo general de estudiar el aprendizaje en base a la teoria científico-psicológica de Galperin. La planificación ha supuesto la Actividad de Situaciones Problemáticas en el Tratamiento de la Información (ASPTI) que, junto con la teoría de Galperin, apoyaron la organización del plan de acción, la hoja de la observación y la secuencia didáctica. El estudio se convirtió en una investigación de acción estratégica de enfoque cualitativo. Los resultados mostraron el desarrollo de habilidades y

\footnotetext{
${ }^{1}$ Mestre em Ensino de Ciências pela Universidade Estadual de Roraima (UERR); Especialista em Gestão Pedagógica (UNINTER); Graduada em Matemática (UERR) e Pedagogia (FACETEN); Professora no Colégio de Aplicação da Universidade Federal de Roraima (UFRR). E-mail: soraya.feitosa@ufrr.br

${ }^{2}$ Mestre em Ensino de Ciências (UERR); Especialista no ensino de Física e Matemática (UNINTER); Graduada em Física (UERR); Professora na Rede Estadual de Educação (SEED/RR). E-mail: ro_zzer@yahoo.com.br ${ }^{3}$ Doutor em Ciências Técnicas pela Universidade Central de Las Villas, Cuba; Bacharel em Física pela Universidade da Havana; Professor no Mestrado Profissional em Ensino de Ciências (UERR). E-mail: tintorer.delgado@gmail.com
} 


\section{HORIZONTES - REVISTA DE EDUCAÇÃO}

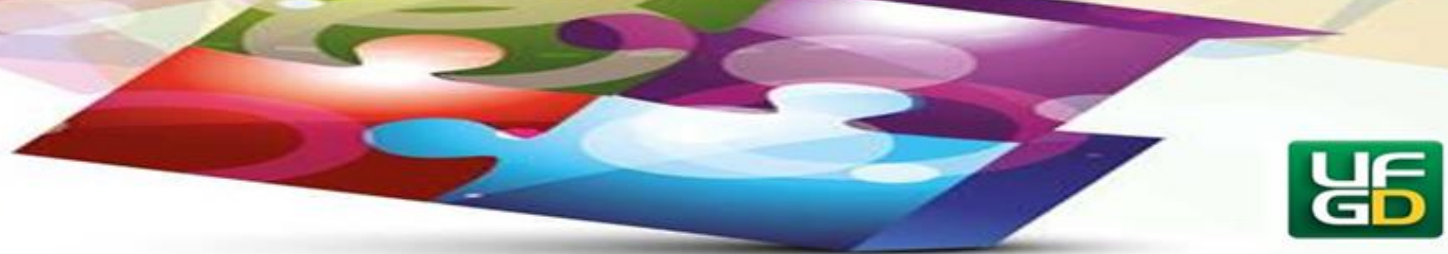

competencias y mejora en el rendimiento estudiantil en las acciones y operaciones de ASPTI en Unidades de Medida del Tiempo.

Palabras clave: Aprendizaje. La Teoría de Galperin. El ASPTI.

\section{Introdução}

Este trabalho é componente do planejamento didático elaborado e executado no âmbito do Mestrado Profissional em Ensino de Ciências. Trata-se da $2^{\mathrm{a}}$ fase da pesquisa caracterizada como investigação no ambiente escolar que objetivou estudar a aprendizagem discente no Bloco de Tratamento da Informação. Este bloco foi selecionado, juntamente com as unidades de medida de tempo, pois além de fazerem parte do cotidiano, permitem relacionar diversos conteúdos matemáticos e favorecem o aprofundamento de conceitos e procedimentos, não somente na matemática, mas de forma interdisciplinar.

Assim como o Tratamento da Informação e Unidades de Medida de Tempo, a Resolução de Problemas também está presente no dia-a-dia do homem sendo importante instrumento para atuar em sociedade e compreender o mundo, pois proporciona um espírito de busca e desenvolve competências. Além disso, a matemática é uma forma de compreender e atuar no mundo e não pode ser dissociada da realidade estudantil.

Por buscar a desfragmentação curricular esta pesquisa trouxe a proposta de relacionar a Atividade de Situações Problema aos blocos matemáticos de Tratamento da Informação e Unidades de Medida de Tempo visando um ensino pautado no desenvolvimento de habilidades e competências.

A pesquisa desenvolvida teve como problema o seguinte: A Atividade de Situações Problema irá melhorar a aprendizagem no Tratamento da Informação na Educação Matemática a partir da Teoria de Formação por Etapas das Ações Mentais? Para responder a esta problemática foi elaborado o seguinte objetivo geral: Estudar a aprendizagem dos alunos na Atividade de Situações Problema no Tratamento da Informação no $6^{\circ}$ ano do Ensino Fundamental a partir da Teoria de Formação por Etapas das Ações Mentais. Os objetivos específicos foram: Diagnosticar o conhecimento do aluno quanto à Resolução de Problemas e Tratamento da Informação; Construir a Atividade de Situações Problema no Tratamento da Informação a partir da Teoria de Formação por Etapas das Ações Mentais; Construir a Base 


\section{HORIZONTES - REVISTA DE EDUCAÇÃO}

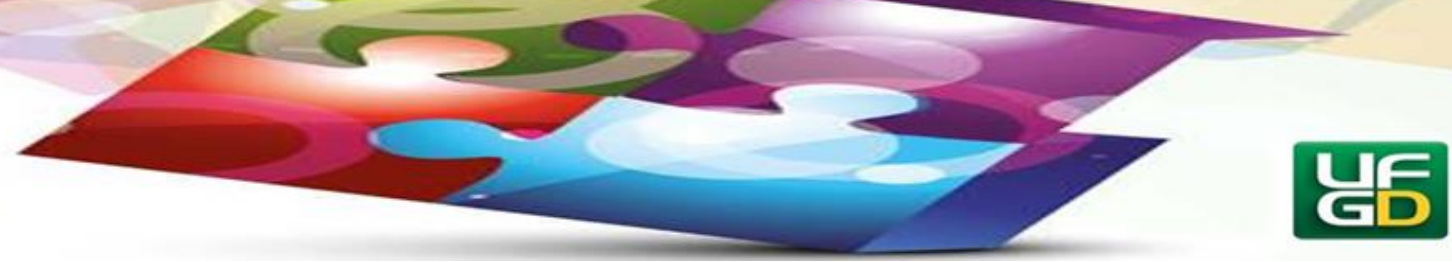

Orientadora da Ação para trabalhar a Atividade de Situações Problema no Tratamento da Informação em cada conteúdo/bloco matemático e Avaliar o desenvolvimento cognitivo dos alunos na Atividade de Situações Problema no Tratamento da Informação.

Para responder à problemática e alcançar os objetivos delineados esta pesquisa adotou como filosofia o Materialismo Dialético tendo como referência a Teoria Histórico-Cultural cujo precursor foi Vygotsky. Fundamentou-se na Teoria da Atividade de Leontiev e, mais especificamente, na Teoria de Formação por etapas das Ações Mentais de P. Ya Galperin, por meio da qual foram planejadas as etapas da pesquisa, o plano de ações, e a sequência didática.

\section{Ensino de Matemática e a Teoria de Galperin}

Compreender que a matemática é um conjunto de conhecimentos acabados torna a aula meramente expositiva e não abre espaços para a criação e participação ativa do aluno, por isso os PCN's (1998) enfatizam que esse obstáculo deve ser superado em prol de uma Educação Matemática de qualidade e indicam como ponto indispensável a preparação e atuação docente em que, ao lançar mão de práticas educacionais, o professor entenda a matemática como ciência dinâmica ao passo que construa um sólido conhecimento dos conceitos e procedimentos dessa área propiciando a criação de ambientes favoráveis ao aprendizado discente.

De acordo com a Teoria Histórico-Cultural o homem não pode ser entendido separadamente de sua história, seu contexto, sua cultura, pois sua consciência se formou mediante as relações com outras pessoas e mediante sua atividade, "cada um traz em suas condições subjetivas características do tempo, do espaço, da sociedade, e do grupo social no qual se produziu gente" (WITTMANN E KLIPPEL, 2010), pois as relações com as outras pessoas, com o mundo e consigo mesmo vão determinando e constituindo o ser. Nessa perspectiva, o aluno deve ser entendido como um ser social e histórico que possui vivências, experiências e conhecimentos que adquiriu anteriormente, onde o professor precisa estar atento ás particularidades discentes.

Galperin (1983 citado por DUARTE, 2012) enfatizou a importância do professor no processo visto que, para alcançar cada etapa o aluno precisa de direcionamento, pois sem orientação o processo educativo fica comprometido. Nesse sentido, entende-se a Teoria de Formação por Etapas das Ações Mentais como uma importante contribuição de Galperin para 


\section{HORIZONTES - REVISTA DE EDUCAÇÃO}

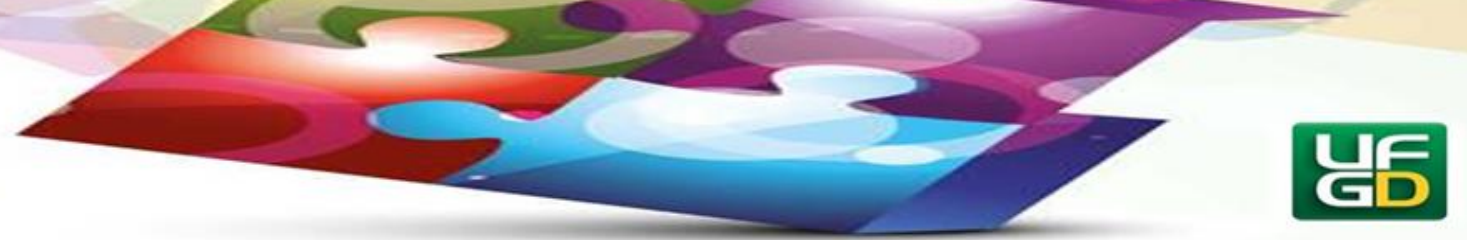

a Teoria da Atividade, pois propõe uma sequência qualitativa para que o indivíduo assimile a informação, o conceito, ou seja, adquira significados.

Nas etapas para assimilar o novo conhecimento, a motivação é definida como etapa zero - E0 ${ }^{4}$. Esta etapa foi acrescentada partindo-se do pressuposto de que se um aluno não está disposto a aprender é impossível ensiná-lo e que, conforme Talízina (1988) aprende-se melhor quando se está motivado. Desta forma, o professor, ao dirigir o processo de ensino e aprendizagem deve criar uma disposição positiva para o estudo, criar ambientes para motivar o aluno, em que este, por sua vez, é entendido como sujeito.

A etapa 1 - E1 - trata-se da Base Orientadora da Ação (BOA) em que o professor orienta o aluno em função do objetivo que pretende alcançar. Esta base de orientação é de fundamental importância para alcançar a qualidade na execução da ação (RIBEIRO, 2012). A utilização da BOA busca a iniciação do aluno no processo de assimilação do conhecimento em que a ação modifique-se da material para a mental. $\mathrm{O}$ docente organiza a sequência didática e orienta $\mathrm{O}$ aluno no processo de assimilação, nas ações que deve seguir (TALÍZINA, 1988, p.58).

Segundo Bassan (2012), Galperin identificou empiricamente três tipos de BOA, neste trabalho foi adotada a do tipo completa, generalizada e independente que será nomeada de BOA B. Essa BOA apresenta uma completa composição por caracterizar-se pela estabilidade e amplitude na transferência de conceitos. Neste caráter generalizado os estudantes recebem orientações necessárias para a realização das ações e desenvolvem a habilidade de transferir os conhecimentos adquiridos para outras situações, é nesse sentido que a BOA com essas características é considerada produtiva (TALÍZINA, 1988 citada por DUARTE, 2012, p.41). Um importante fator na BOA B é que permite ao professor determinar as etapas do processo de ensino e aprendizagem refletindo a estrutura e os procedimentos da atividade, ou seja, permite ao professor o planejamento detalhado.

Na etapa 2 (E2) - Formação da Ação em Forma Material ou Materializada - o aluno trabalha a partir das orientações recebidas, não de forma passiva, mas de forma ativa. Segundo Galperin (1983 citado por RIBEIRO, 2012) nessa etapa as atividades são realizadas por meio de recursos na forma material (objetos reais) ou materializada (representações: desenhos, fotografias, etc.) permitindo ao aluno assimilar o conteúdo da atividade prática tornando-o apto

\footnotetext{
${ }^{4}$ A etapa motivacional foi acrescentada por Talízina como contribuição à Teoria de Galperin e definida como E0 porque além de complementação à teoria não é uma ação, diferentemente das outras etapas.
} 


\section{HORIZONTES - REVISTA DE EDUCAÇÃO}

e-ISSN: 2318-1540

a passar para o próximo nível. Nesse estágio o aluno pode desenvolver a atividade em pares ou em grupos e ser acompanhado pelo professor (NUÑEZ, 2009 citado por BASSAN, 2012).

Na etapa 3 (E3) - Formação da Ação Verbal Externa - o aluno é capaz de explicar o que está fazendo, ou seja, através da fala o aluno propaga a ação, descreve o que faz e como faz, argumentando o caminho percorrido. A linguagem facilita a criação dos signos e pode se dá de diversas formas: verbal, escrita, gestual, musical (BASSAN, 2012).

Na etapa 4 (E4) - Formação da Ação na Linguagem Externa para si - o aluno possui a capacidade de generalizar, pois expressa internamente o conceito e aplica a diferentes situações. A linguagem interna transforma-se em função mental proporcionando novos meios para o pensamento. Essa capacidade de generalização já é esperada no ensino fundamental, pois o conhecimento aprendido pelo aluno não deve estar vinculado a um contexto concreto e único, mas deve poder ser generalizado, ou seja, transferido a outras situações (PCN's, 1998, p. 36).

Na etapa 5 (E5) - Formação da Ação na Linguagem Interna - também conhecida como etapa da automatização. Aqui, o conhecimento torna-se automático para o aluno e ele adquire a capacidade de explicar seu raciocínio utilizando os conceitos em situações diferenciadas.

Nesse contexto, o ensino baseado na Teoria de Formação por Etapas das Ações Mentais é classificado como sistêmico-teórico ${ }^{5}$, em que os estudantes recebem orientações do professor e agem de maneira independente, ou seja, primeiramente o professor colabora no processo de resolução, estimulando a cooperação entre os pares, mas o estudante tem a liberdade de seguir os próprios métodos de resolução podendo solicitar a ajuda docente sempre que tiver necessidade, por isso a orientação tem grande importância no processo educacional sendo entendida como uma especificidade do ensino, pois pode mobilizar o desenvolvimento estudantil.

\section{Delineamento Metodológico}

Este estudo caracteriza-se como pesquisa-ação estratégica de enfoque qualitativo e foi realizado na Escola Estadual Professora Conceição da Costa e Silva em Boa Vista - RR com 21 alunos do $6^{\circ}$ ano do ensino fundamental, cujo o objetivo geral foi estudar a aprendizagem

\footnotetext{
${ }^{5}$ Esta denominação é de ARIEVITCH \& STETSENKO, 2000 in BASSAN 2012, p.13.
} 


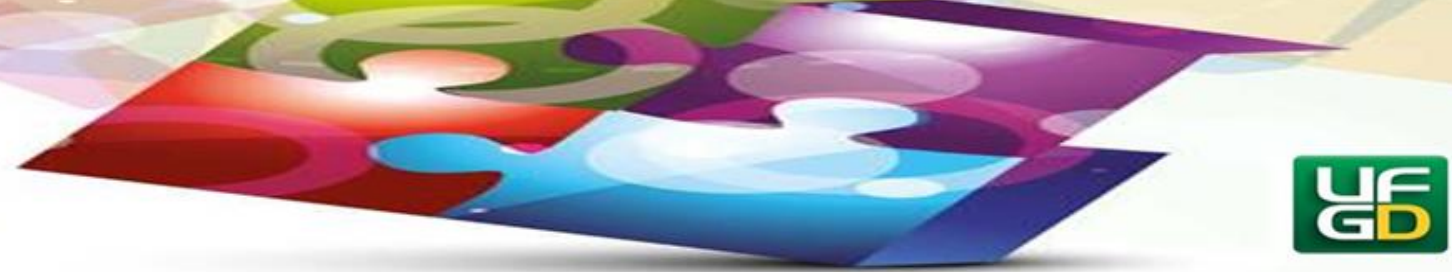

na Atividade de Situações Problema no Tratamento da Informação no Ensino de Matemática a partir da Teoria de Formação por Etapas das Ações Mentais.

O planejamento didático foi dividido em duas fases, cada uma relacionou o bloco de Tratamento da Informação com outros blocos matemáticos com a proposta de desfragmentação curricular. A primeira fase, detalhada em outro $\operatorname{artigo}^{6}$, focou a Atividade de Situações Problema no bloco de Tratamento da Informação com números e operações tendo como objetivo melhorar habilidades discentes relacionadas a interpretação de dados em gráficos e tabelas, Resolução de Problemas e operações básicas da matemática. E esta segunda fase focou a Atividade de Situações Problema no Tratamento da Informação com Unidades de Medida de Tempo visando o desenvolvimento de competências relacionadas à transformação dessas unidades e ampliação da capacidade de construir e solucionar modelos matemáticos que envolvam as quatro operações básicas.

Dessa forma, o planejamento didático foi organizado de acordo com a figura seguinte:

\footnotetext{
${ }^{6}$ Atividade de Situações Problema como Estratégia Didática no Tratamento da Informação
} 


\section{MORIZONTES - REVISTA DE EDUCAÇÃO}

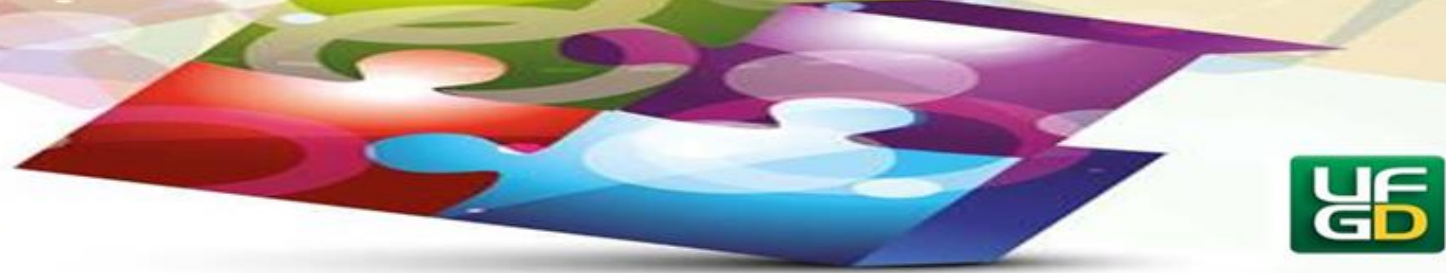

Figura 01: Planejamento didático

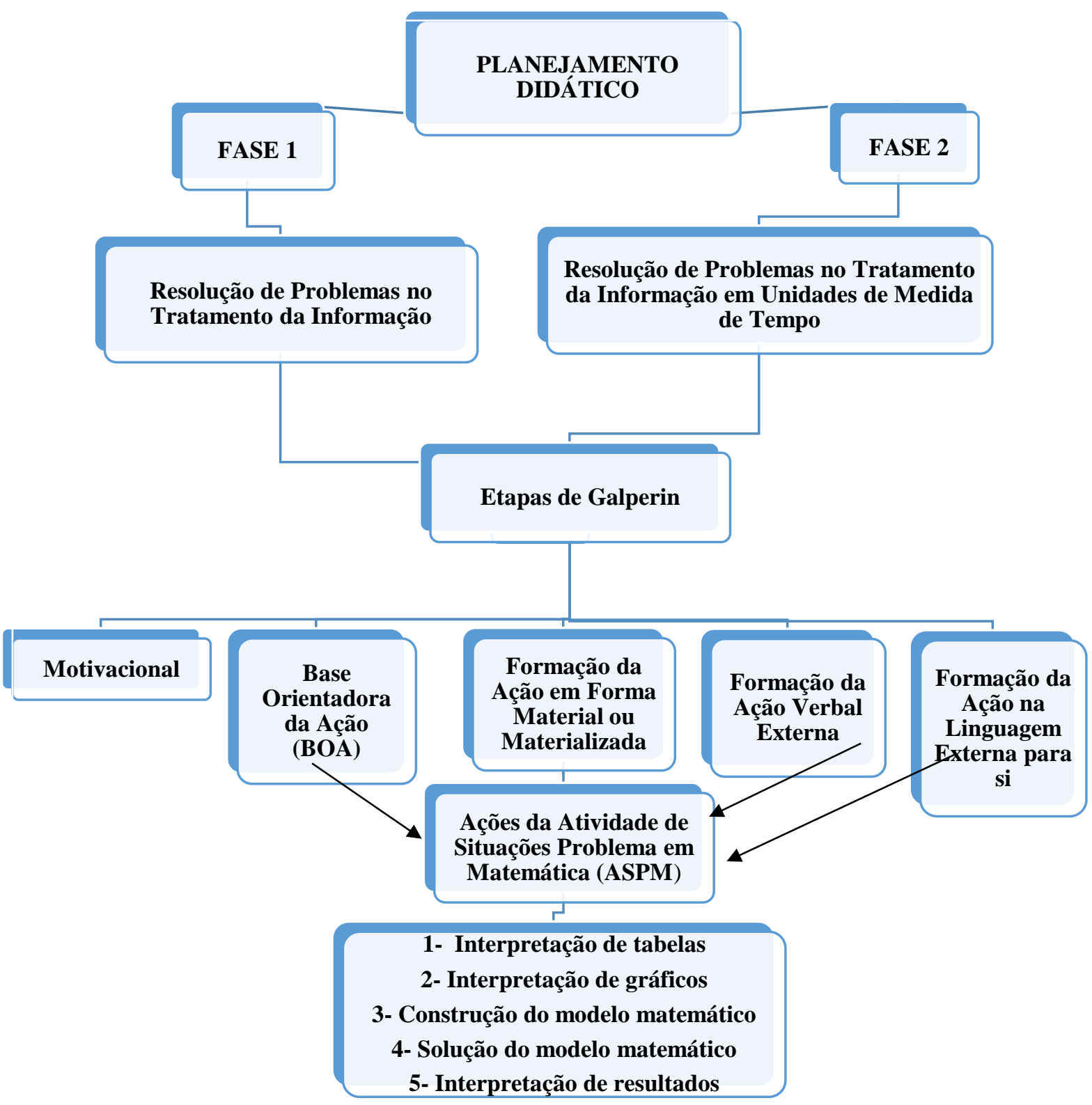

Fonte: Feitosa (2014).

Cada etapa de Galperin teve objetivo traçado: A BOA teve como meta orientar os alunos para o cumprimento das ações buscando desenvolver habilidades de leitura e interpretação dos problemas, compreensão dos dados expostos nos gráficos e tabelas e definição dos objetivos do problema; a materializada visou o desenvolvimento de habilidades e competências na resolução de problemas-tipo; a verbalizada buscou a ação verbal e/ou escrita do aluno com elaboração de 


\section{HORIZONTES - REVISTA DE EDUCAÇÃO}

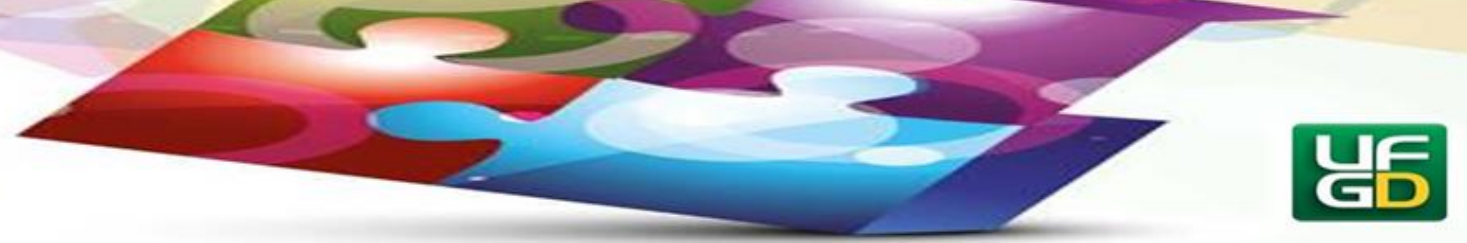

hipóteses, exposição de argumentos e ideias; e a etapa de generalização teve como meta desenvolver a capacidade de transferência para outros contextos.

Em todas as etapas da pesquisa foram trabalhadas as ações e operações da ASPTI (Atividade de Situações Problema no Tratamento da Informação), uma estratégia didática fundamentada na ASPM (Atividades de Situações Problema em Matemática), elaborada por Mendoza e Tintorer (2012) a partir da Teoria da Atividade e da Teoria de Formação por Etapas das Ações Mentais, e constitui-se na conversão da Resolução de Problemas em uma atividade de estudo. A ASPTI foi adaptada para o contexto do ensino fundamental assumindo a seguinte forma:

Tabela 01: ASPTI - Sistema de ações e operações

\begin{tabular}{lll}
\hline \multicolumn{1}{c}{ Ações } & \multicolumn{1}{c}{ Operações } \\
\hline $\begin{array}{l}\text { 1. Compreender } \\
\text { problema }\end{array}$ & $\begin{array}{l}\text { a) Ler o problema e extrair os elementos desconhecidos } \\
\text { b) Estudar e compreender os elementos desconhecidos } \\
\text { c) Determinar os dados e as condições } \\
\text { d) Determinar os objetivos do problema }\end{array}$ \\
$\begin{array}{l}\text { 2. Construir } \\
\text { modelo } \\
\text { matemático }\end{array}$ & $\begin{array}{l}\text { a) Determinar a sequência necessária das operações matemáticas } \\
\text { b) Realizar a análise das unidades de medida do modelo }\end{array}$ \\
$\begin{array}{l}\text { 3. Solucionar } \\
\text { Problema }\end{array}$ & $\begin{array}{l}\text { a) Executar a sequência } \\
\text { b) Solucionar o modelo }\end{array}$ \\
$\begin{array}{l}\text { 4. Interpretar } \\
\text { solução }\end{array}$ & $\begin{array}{l}\text { a) Interpretar o resultado obtido na solução do modelo } \\
\text { b) Extrair resultado significativo que tenha relação com o objetivo do problema } \\
\text { c) Dar respostas aos objetivos do problema } \\
\text { d) Analisar a partir de novos dados/condições que tenham relação direta ou não com } \\
\text { os objetivos do problema, a possibilidade de reformular o problema, construir } \\
\text { novamente o modelo, solucionar. }\end{array}$ \\
\hline
\end{tabular}

Fonte: Adaptada de Mendoza (2012) e Mendoza \& Tintorer (2012).

Durante a sequência didática elaborou-se uma planilha de observação que foi montada de acordo com os fundamentos da Teoria de Formação por Etapas das Ações Mentais e levou em consideração três pilares: motivação $e$ interesse que teve como parâmetro o empenho e dedicação nas atividades propostas; verbalização que analisou ações atitudinais de comunicação de ideias e argumentos; e independência que observou se o aluno era ativo e se realizou as atividades independentemente. Essa planilha permitiu o acompanhamento em cada ação da ASPTI, em cada uma das etapas de Galperin e nas fases do planejamento didático, viabilizando a percepção da motivação discente e das ações em que apresentavam maiores dificuldades. 


\section{HORIZONTES - REVISTA DE EDUCAÇÃO}

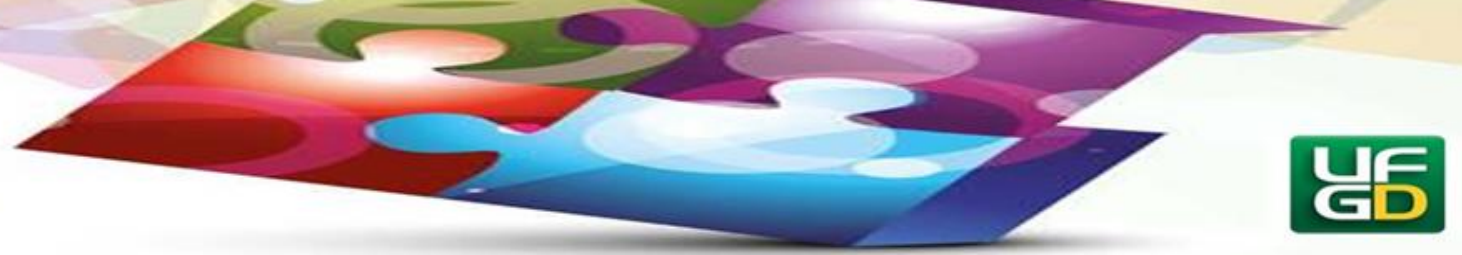

Também foram utilizados como instrumentos de coleta de dados entrevista, avaliações escritas e exposição verbal. Estes instrumentos são explicados, detalhadamente, no artigo que trata da $1^{a}$ fase do planejamento didático ${ }^{7}$. O último instrumento utilizado foi o pós-teste elaborado com objetivo de analisar o desenvolvimento discente após a sequência didática. Foi aplicado dois meses após o fim das fases do planejamento, tendo em sua composição 03 questões mistas em que cada uma avaliou competências e habilidades conforme a tabela:

Tabela 02: Característica e competência envolvida nas questões do pós-teste

\begin{tabular}{lcl}
\hline \multicolumn{1}{c}{ Questão } & Característica & \multicolumn{1}{c}{ Competência } \\
\hline $\mathbf{1} \mathbf{a}$ & Aberta & Coleta de dados em gráficos \\
$\mathbf{1} \mathbf{b}$ & Aberta & Coleta, organização e interpretação de dados em gráficos \\
$\mathbf{1} \mathbf{c}$ & Aberta & Resolução de Problemas a partir de dados em gráficos \\
$\mathbf{1} \mathbf{d}$ & Aberta & Resolução de Problemas a partir de dados em gráficos \\
$\mathbf{2}$ & Fechada & $\begin{array}{l}\text { Interpretação de dados e Resolução de Problemas a partir de } \\
\text { dados em tabelas }\end{array}$ \\
$\mathbf{3}$ & Aberta & Coleta, organização e interpretação de dados em tabelas \\
$\mathbf{3 b}$ & Aberta & Resolução de problemas em tabelas \\
$\mathbf{3 c}$ & Aberta & Resolução de problemas em tabelas \\
$\mathbf{3 d}$ & Aberta & Resolução de problemas em tabelas \\
3e & Aberta & Resolução de problemas em tabelas \\
3f & Aberta & Construção de gráfico a partir de informações em tabela \\
\hline
\end{tabular}

Fonte: Feitosa (2014).

Este pós-teste foi elaborado em harmonia com o pré-teste, ou seja, composto por questões que avaliaram as mesmas habilidades e competências, visando a posterior comparação entre tais instrumentos e a avaliação do desenvolvimento discente durante a pesquisa.

Os instrumentos de coleta de dados utilizados são considerados válidos visto que foram organizados em coerência com a Teoria de Formação por Etapas das Ações Mentais, levando em conta a contextualização, a motivação discente, as particularidades de cada aluno, o objetivo de ensino e as variáveis do contexto pesquisado. Na sequência, são apresentados os instrumentos e seus objetivos:

\footnotetext{
${ }^{7}$ Intitulado: Atividade de Situações Problema como Estratégia Didática no Tratamento da Informação.
} 


\section{MORIZONTES - REVISTA DE EDUCAÇÃO}

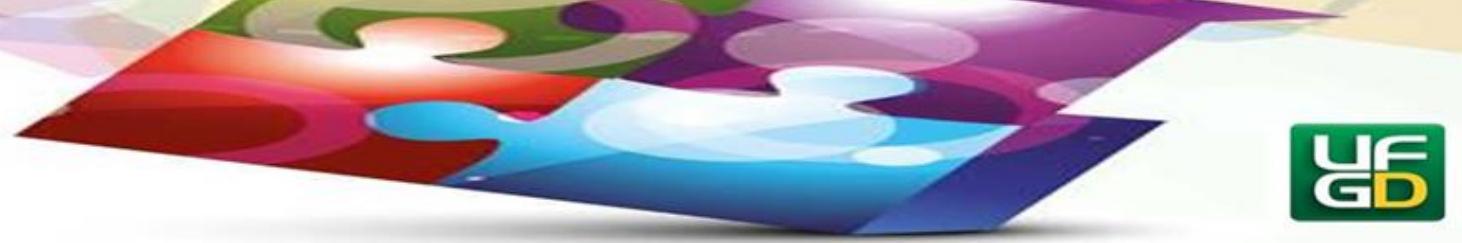

Figura 02: Instrumentos de coleta

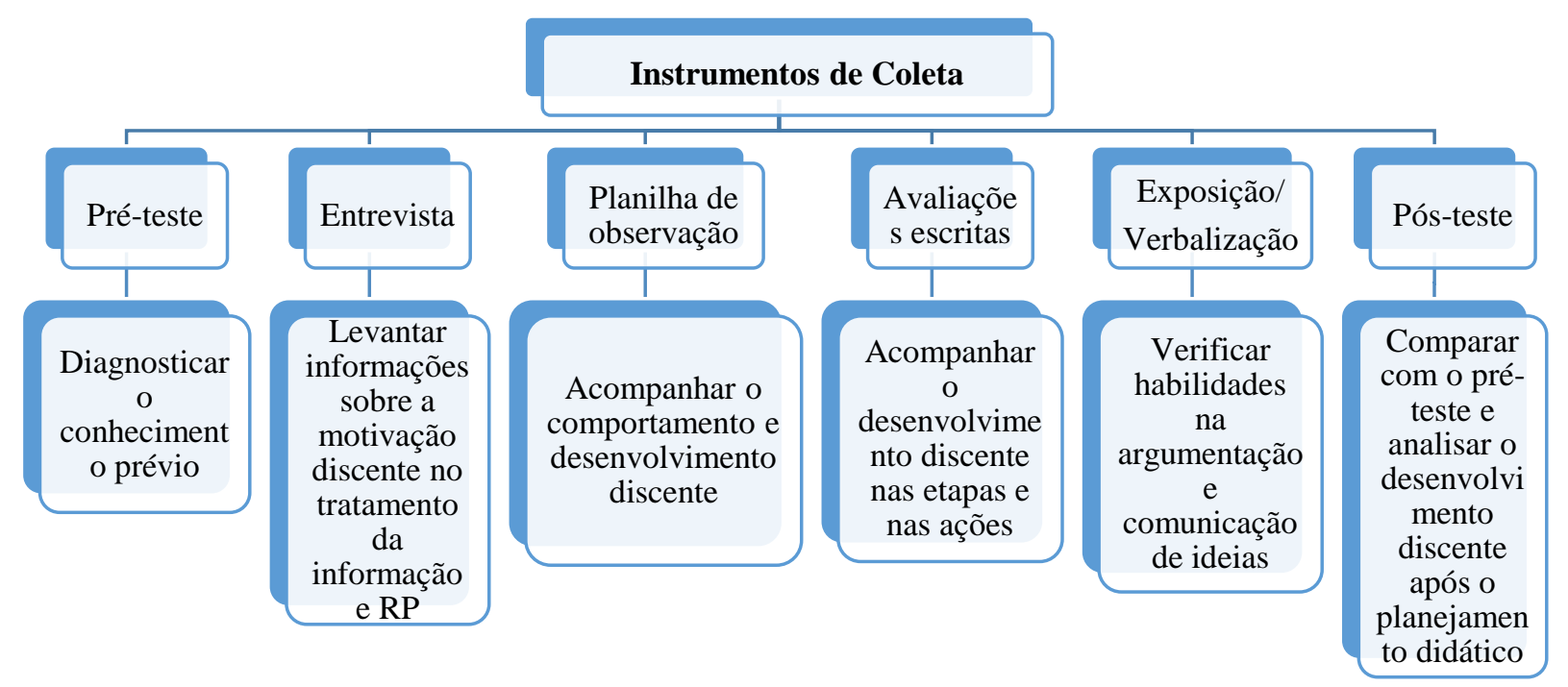

Fonte: Feitosa (2014).

Como se observa na figura 02 , cada instrumento utilizado na coleta de dados foi organizado de acordo com um objetivo e foi elaborado com base num referencial teórico, o que contribui na utilização de meios confiáveis para obtenção de informações.

A validade e confiabilidade dos instrumentos de coleta utilizados nesta pesquisa devemse ao método de triangulação, que "implica na utilização de abordagens múltiplas para evitar distorções em função de um método, uma teoria ou um pesquisador" (GÜNTHER, 2006, p. 206). Entre os tipos de triangulação este é caracterizado como triangulação de dados que consiste na utilização de "diferentes fontes de dados ou de informações para se chegar ao mesmo resultado" (OLLAIK E ZILLER, 2012, p. 234). Além de utilizar avaliações em cada etapa também foram realizadas observações durante o processo da pesquisa, fator que contribuiu para minimizar erros e enriquecer os dados coletados.

\section{Resultados e Discussão}

Esta sequência do planejamento caracteriza-se como um processo de retroalimentação que visou sanar as deficiências encontradas na fase anterior. O conteúdo de Unidades de Medida de Tempo (UMT's) foi escolhido tendo como base os PCN's de matemática (1998, p.69) que apontam entre os objetivos do $3^{\circ}$ ciclo o desenvolvimento das competências métricas onde os alunos sejam capazes de resolver problemas que envolvam diferentes grandezas e selecionem as unidades de medidas e os instrumentos adequados e, no caso das unidades de medida de 


\section{HORIZONTES - REVISTA DE EDUCAÇÃO}

tempo, que sejam capazes de utilizar relógios, cronômetros, calendários, entre outros. Além disso, os PCN's (1998) recomendam que as situações-problema com UMT's estejam relacionadas ao contexto do aluno para que percebam suas aplicações práticas e consigam converter as unidades mais usuais. A Base Orientadora da Ação levou em consideração tais habilidades e competências e teve como objetivo melhorar o desempenho discente relacionado à leitura e interpretação de dados em formatos gráficos, bem como ampliar conceitos matemáticos relacionados a hora, minuto e segundo, sendo capaz de determinar quais unidades de medida de tempo o problema utiliza.

O conteúdo teve início com a exposição da utilização de gráficos e tabelas em diversas situações cotidianas que apresentavam unidades de medida de tempo, como corridas da fórmula 1, partidas de vôlei e outros tipos de jogos, tempos de deslocamentos, etc. Tal exposição objetivou despertar o interesse e a motivação discente. Em seguida deu-se início à BOA que foi caracterizada do tipo B, ou seja, completa, generalizada (orientações inicialmente essenciais e abrangentes do conceito e, posteriormente particulares, específicas) e independente (os alunos adquirem independência no desenvolvimento das operações e apropriação das ações). De acordo com Duarte (2012, p. 42) essa BOA é considerada eficiente, visto que os alunos cometem poucos erros e desenvolvem habilidades que ampliam a transferência para outras situações.

Assim como na $1^{\text {a }}$ fase, as orientações da BOA foram organizadas de acordo com as ações e operações da ASPTI, os alunos foram orientados, inicialmente, a ler o problema, extrair os elementos desconhecidos para buscar sua compreensão e determinar os objetivos do problema. O quadro seguinte é um exemplo que foi trabalhado na etapa de orientações:

Quadro 01: Atividade trabalhada na BOA em Unidades de Medida de Tempo ${ }^{8}$

Ex. 2) A tabela fornece a duração de cada set de uma partida de vôlei.

\begin{tabular}{|l|l|}
\hline Set & Duração \\
\hline $1^{\text {o }}$ & $80 \min$ \\
\hline $2^{\text {o }}$ & $1 \mathrm{~h} 03$ min \\
\hline $3^{\text {o }}$ & $1 \mathrm{~h} 25 \mathrm{~min}$ \\
\hline
\end{tabular}
a) Qual foi o set mais duradouro?
b) Qual set durou menos tempo?
c) Quantos minutos durou o $2^{\circ}$ set?
d) Quantos segundos durou o $1^{\circ}$ set?
e) Qual a duração total do jogo?

\footnotetext{
${ }^{8}$ Questão adaptada do livro: BONJORNO, José Roberto. Matemática pode contar comigo. $4^{\circ}$ ano. - São Paulo: FTD, 2008. (Desafio, p.61).
} 


\section{HORIZONTES - REVISTA DE EDUCAÇÃO}

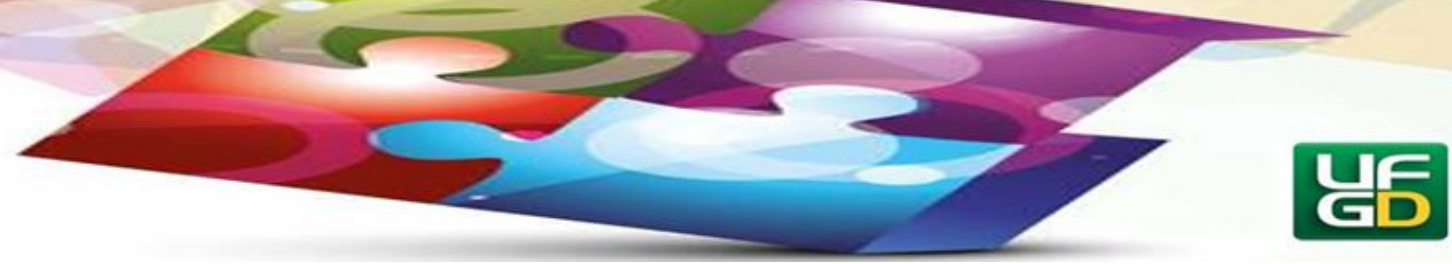

Aqui os alunos foram direcionados em relação à interpretação dos dados por isso foram incentivados a descrever as informações e indagados sobre o significado das seguintes expressões: gastou mais tempo e gastou menos tempo, rápido e duradouro, e orientações sobre as relações entre hora, minuto e segundo. Posteriormente, as orientações foram dadas quanto à construção do modelo matemático e solução problema. Nessa etapa os alunos foram perguntados sobre a necessidade de conversões nas unidades de medida de tempo, sobre as operações matemáticas necessárias para converter as unidades e sobre a sequência adequada das operações para encontrar a solução. Ao final, as orientações estavam relacionadas à interpretação dos resultados e em responder aos objetivos do problema. Esta etapa de orientações teve duração de 3 horas.

$\mathrm{Na} \mathrm{BOA} \mathrm{B}$ as atividades foram elaboradas conjuntamente. Os alunos desenvolveram habilidades na elaboração de hipóteses e comunicação de ideias, pois foram inseridos na problemática com questões contextualizadas, como por exemplo: como faço para transformar horas em minutos? E minutos em horas? Um minuto corresponde a quantos segundos? E uma hora? Além disso, trabalhou-se a montagem de relógios na sala, onde cada aluno se dirigia ao quadro para desenhar os ponteiros de determinada hora.

A utilização da planilha de observação foi muito importante nesta etapa, pois permitiu analisar a participação dos estudantes e perceber aqueles que estavam dispersos, direcionando a estes alunos questões que os faziam buscar respostas e voltar à discussão da sala. Essa dinâmica diminui a dispersão discente e aumentou a participação, os alunos estavam interessados pelos problemas e mostravam ânimo e interesse nas aulas, por vezes foi necessário solicitar a alguns alunos que deixassem os outros participar, porque eles começavam a falar e não paravam mais.

Após a BOA iniciou-se a etapa de formação da ação em forma material ou materializada que teve duração de 4 horas, em que os alunos trabalharam a partir das orientações dadas para resolver problemas-tipo.

Por meio da planilha de observação foi possível constatar que durante a etapa materializada da $2^{\text {a }}$ fase do planejamento os alunos estavam mais motivados que anteriormente e participavam ativamente das aulas. Tal situação gerou mudanças no rendimento discente.

Ao comparar os resultados percebeu-se que dois alunos melhoraram o desempenho passando de regular para bom, pois apresentaram nesta $2^{\text {a }}$ fase poucas dificuldades na solução 


\section{HORIZONTES - REVISTA DE EDUCAÇÃO}

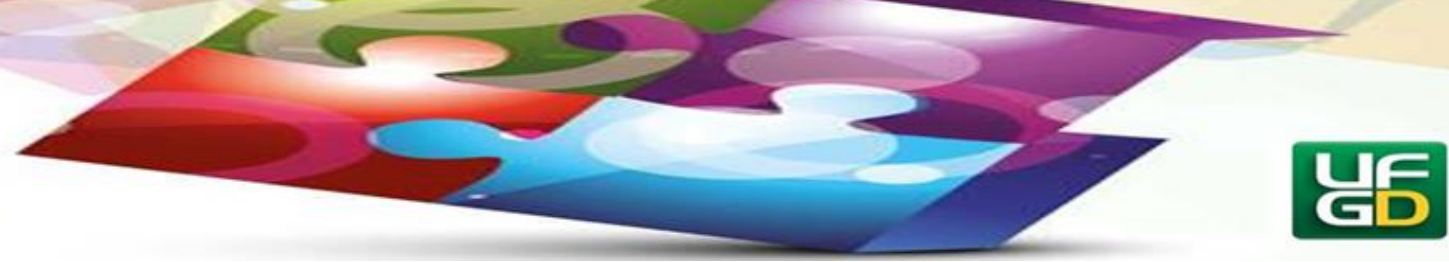

do problema e interpretação de resultados. Porém, três alunos que tinham alcançado bom desempenho na fase anterior caíram para regular nesta materializada, tal resultado deve-se às dificuldades na conversão de unidades de medida de tempo que fez os alunos se confundirem na montagem do modelo adequado para solucionar o problema. Não se pode, no entanto, afirmar que houve retrocesso no desempenho desses discentes, pois o grau de dificuldade desta fase do planejamento é maior que o da $1^{\text {a }}$ fase, já que foi acrescentado o conteúdo de unidades de medida e tempo. O que se pode apontar é que tais alunos não superaram totalmente algumas das dificuldades quanto a conversões e construção do modelo. Os demais alunos permaneceram com o mesmo desempenho da fase anterior do planejamento o que indica progresso, pois conforme já foi dito, o grau de dificuldade de uma fase para outra aumentou, exigindo dos alunos maiores habilidades e competências para resolver os problemas no bloco de Tratamento da Informação.

Como sequência do planejamento didático iniciou-se a etapa de verbalização que, conforme o planejamento, constou da explicação de determinada situação problema e teve duração de 3 horas apresentando os seguintes resultados:

Tabela 03: Resultados da verbalização em Unidades de Medida de Tempo

\begin{tabular}{|c|c|c|}
\hline Conceito & Total & $\%$ \\
\hline $\begin{array}{l}\text { 1-Verbalizou explicando as resoluções sem apresentar } \\
\text { dificuldades }\end{array}$ & 11 & $52,38 \%$ \\
\hline $\begin{array}{l}\text { 2-Verbalizou, mas apresentou dificuldades na montagem do } \\
\text { modelo matemático }\end{array}$ & 5 & $23,81 \%$ \\
\hline $\begin{array}{l}\text { 3-Verbalizou, mas apresentou dificuldades no conhecimento } \\
\text { matemático ( } 4 \text { operações) }\end{array}$ & 5 & $23,81 \%$ \\
\hline
\end{tabular}

Aqui, observou-se um progresso no desempenho da turma, um salto qualitativo, já que a maioria dos alunos verbalizou adequadamente, sem dificuldades, explanando e apresentando as ações e operações utilizadas no decorrer da resolução do problema.

Logo após a conclusão da verbalizada iniciou-se a etapa de generalização que teve como objetivo analisar a capacidade de transferência, ou seja, se os alunos conseguiram trabalhar em novo contexto. Esta etapa teve duração de três horas e apresentou os resultados da sequência: 


\section{HORIZONTES - REVISTA DE EDUCAÇÃO}

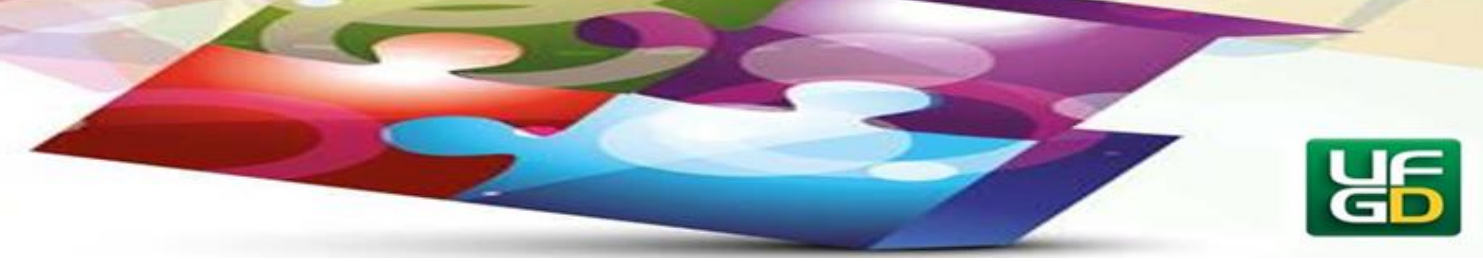

Tabela 04: Resultados da etapa generalizada

\begin{tabular}{cccccc}
\hline Aluno & Conceito & Aluno & Conceito & Aluno & Conceito \\
\hline A1 & B & A8 & R & A15 & B \\
A2 & B & A9 & R & A16 & R \\
A3 & R & A10 & R & A17 & R \\
A4 & R & A11 & B & A18 & R \\
A5 & R & A12 & B & A19 & B \\
A6 & R & A13 & R & A20 & R \\
A7 & R & A14 & B & A21 & R \\
\hline
\end{tabular}

Fonte: Feitosa (2014).

Observa-se que 14 alunos apresentaram rendimento regular (confundiram informações e responderam incorreto na maioria das vezes) devido ás dificuldades em interpretar os dados em contextos diferentes dos trabalhados em sala, essa dificuldade no entendimento do problema provocou confusões na conversão de unidades de medida de tempo e na montagem do modelo. Tal situação reforça que para começar a resolver um problema é necessário primeiramente interpretá-lo e extrair informações necessárias para, posteriormente, iniciar o processo de resolução. Nesse caso, como os alunos não sabiam ou não entenderam claramente o que o problema pedia confundiram-se durante as conversões e montagem do modelo.

Os outros 7 alunos apresentaram rendimento bom (responderam correto na maioria das vezes), tendo em vista que conseguiram interpretar os dados das representações gráficas, porém apresentaram algumas dificuldades na interpretação dos resultados, como por exemplo, montar o modelo e resolver o problema adequadamente, mas utilizar a unidade de medida errada para justificar o resultado. Desta maneira, na etapa de generalização dois terços da turma tiveram desempenho regular e um terço apresentou bom desempenho.

Dois meses após o fim da $2^{\mathrm{a}}$ fase foi aplicado o pós-teste com objetivo de verificar o desenvolvimento discente após a sequência didática, ou seja, verificar a contribuição da Atividade de Situações Problema no Bloco de Tratamento da Informação para a aprendizagem. E ao comparar os resultados do pré e pós-teste obteve-se o seguinte gráfico: 


\section{HORIZONTES - REVISTA DE EDUCAÇÃO}

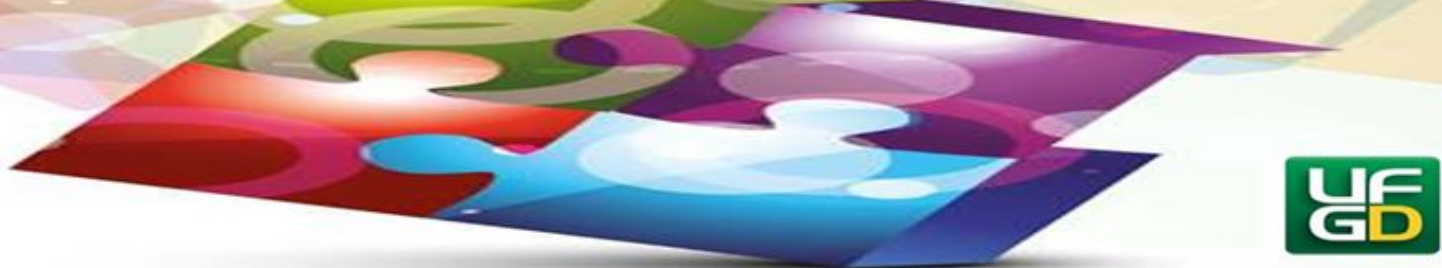

Gráfico 01: Comparação Pré e Pós-teste

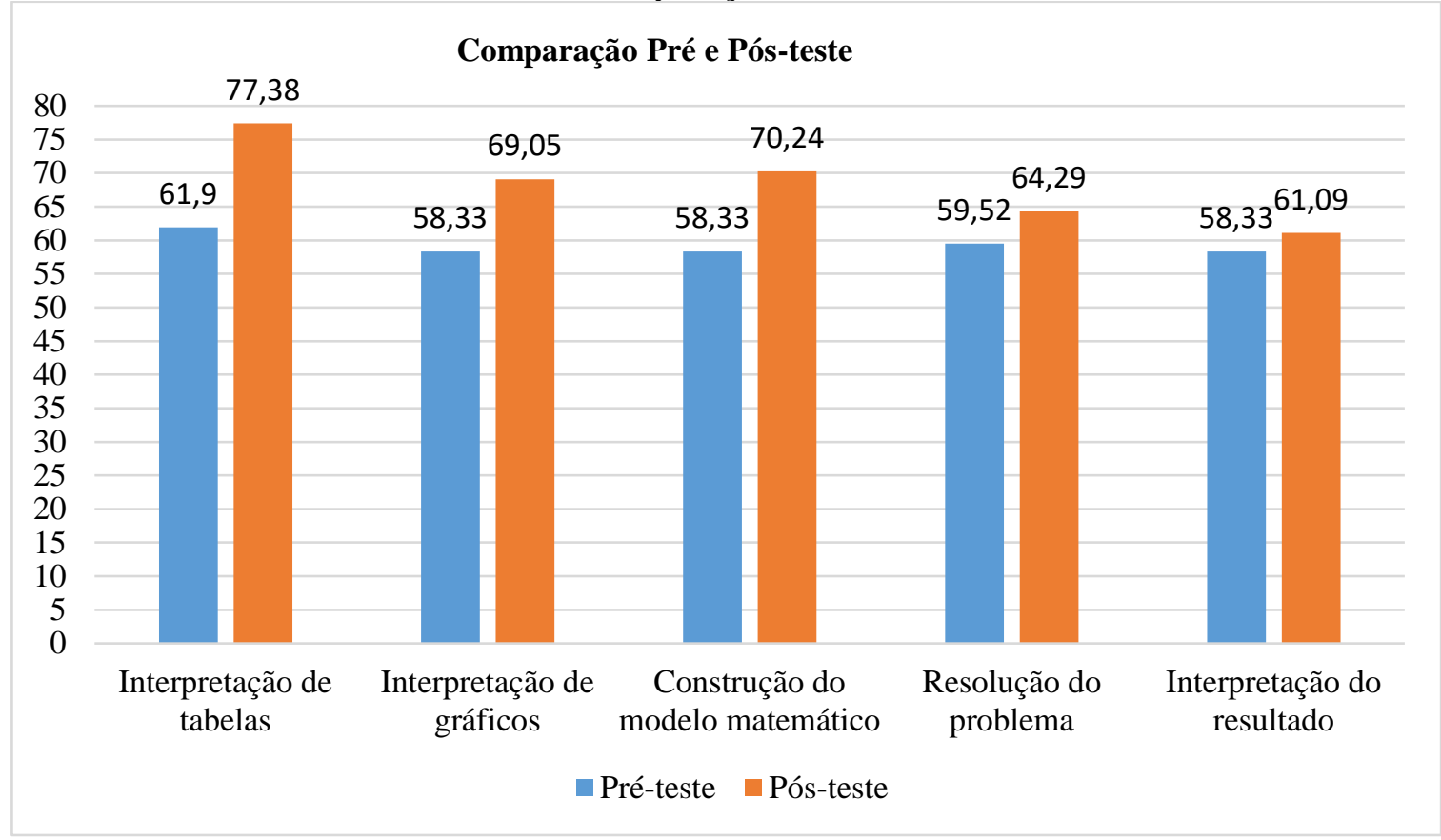

Fonte: Feitosa (2014).

A visualização do gráfico permite a percepção do crescimento discente quanto às ações da ASPTI e a análise dos resultados de desempenho confirmam uma melhora em todas as ações da ASPTI, principalmente na interpretação de tabelas, interpretação de gráficos e na construção do modelo.

\section{Considerações Finais}

Conforme dito na $1^{\mathrm{a}}$ fase, o objetivo geral desta pesquisa foi estudar a aprendizagem dos alunos de $6^{\circ}$ ano na ASPTI a partir da Teoria de Formação por Etapas das Ações Mentais. Para isso foram elaborados quatro objetivos específicos: diagnosticar o ponto de partida do aluno quanto à Resolução de Problemas e Tratamento da Informação. Objetivo que foi alcançado por meio da realização do pré-teste no qual se perceberam as dificuldades discentes na interpretação de dados em gráficos e tabelas e defasagens em conhecimentos básicos da matemática como as quatro operações. 


\section{HORIZONTES - REVISTA DE EDUCAÇÃO}

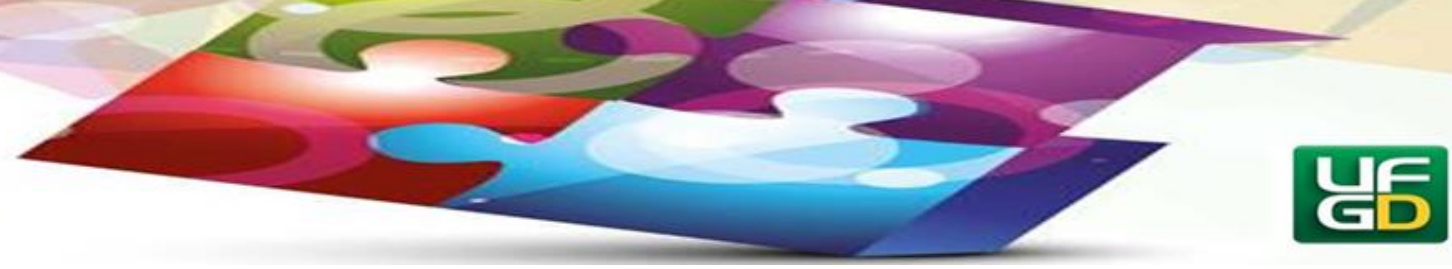

O segundo objetivo específico contemplou a construção da ASPTI enquanto estratégia didática, em que se apresentou uma dinâmica de ações e operações para direcionar a atividade de ensino. O terceiro objetivo direcionou-se à construção da Base Orientadora da Ação para trabalhar a ASPTI em cada conteúdo/bloco matemático e foi realizado em cada fase da pesquisa. $\mathrm{O}$ último objetivo enfatizou a avaliação do desenvolvimento na estratégia didática elaborada. Todos os objetivos específicos foram realizados e confirmaram que a ASPTI despertou o interesse e envolveu os discentes nas atividades propostas.

Entre as etapas de Galperin trabalhadas na pesquisa as melhores vencidas, ou seja, aquelas em que os alunos apresentaram melhor rendimento foram a BOA, visto que os alunos entenderam as orientações e participaram das aulas respondendo aos questionamentos e contribuindo com hipóteses; a materializada em que desenvolveram a atividade de maneira satisfatória e a verbalizada por explanarem de forma escrita e/ou falada suas hipóteses, argumentos e ideias. Desta forma, acredita-se que esta pesquisa deu o passo inicial no desenvolvimento da capacidade de generalização.

Após todo o processo é possível responder que a Base Orientadora da Ação, elaborada dentro da realidade escolar e observando as necessidades e particularidades discentes, direcionou o trabalho docente e favoreceu a elaboração de um planejamento voltado a sanar as dificuldades discentes apresentadas no teste diagnóstico. Por meio da BOA B foram definidos os objetivos de ensino e estes viabilizaram o desenvolvimento discente. Desta forma, infere-se que a ASPTI, enquanto atividade de ensino, adéqua-se à Educação Matemática, pois melhorou a aprendizagem dos alunos do $6^{\circ}$ ano do Ensino Fundamental da Escola Estadual Professora Conceição da Costa e Silva no bloco de Tratamento da Informação, visto que desenvolveram habilidades e competências relacionadas à interpretação de dados em gráficos e tabelas e argumentação de ideias.

Nesse sentido, a Atividade de Situações Problema no Tratamento da Informação apresenta-se como importante estratégia didática para se trabalhar unidades de medida de tempo no $6^{\circ}$ ano do Ensino Fundamental.

\section{Referências}

BASSAN, Larissa Helyne. Teoria da Formação das Ações Mentais por Etapas, de P. Galperin, e o Processo de Humanização. 2012. 113f. Tese (Doutorado em Educação) - 


\section{HORIZONTES - REVISTA DE EDUCAÇÃO}

e-ISSN: 2318-1540

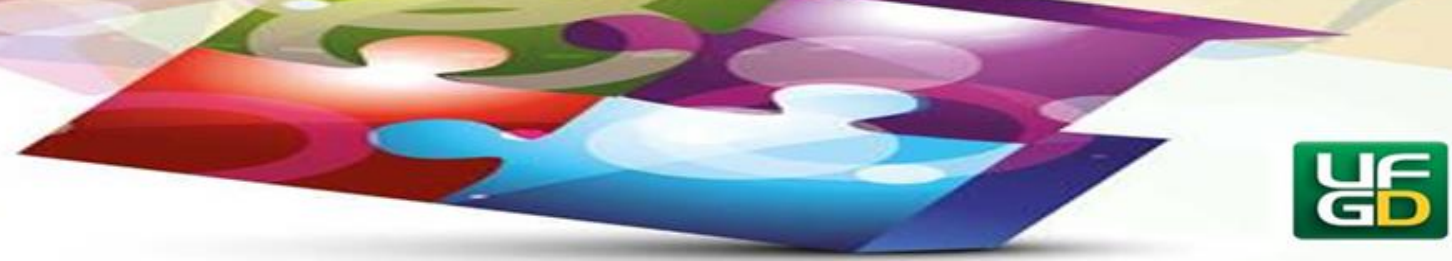

Faculdade de Filosofia e Ciência da Universidade Estadual Paulista Júlio de Mesquita Filho, Campos de Marília. Disponível em:

<https://repositorio.unesp.br/bitstream/handle/11449/102227/bassan_lh_dr_mar.pdf?sequence $=1 \&$ isAllowed $=\mathrm{y}>$. Acesso em $10 \mathrm{JUN} 2012$.

Brasil. Secretaria de Educação Fundamental. Parâmetros Curriculares Nacionais:

Matemática / Secretaria de Educação Fundamental. Brasília: MEC / SEF, 1998.

DUARTE, Daiana Matias. $O$ ensino do conceito de função afim: uma proposição com base na teoria de Galperin. 2011. 94f. Dissertação (Mestrado em Educação) - Universidade do Extremo Sul Catarinense - UNESC, Criciúma.

FEITOSA, Soraya de Araújo. A atividade de situações problema como estratégia didática no tratamento da informação no $6^{\circ}$ ano do ensino fundamental a partir da teoria de Galperin. 2014. 147f. Dissertação (Mestrado em Ensino de Ciências) - Universidade Estadual de Roraima, Boa Vista.

GÜNTHER, Hartmut. Pesquisa qualitativa versus pesquisa quantitativa: esta é a questão? Scielo, Brasília, Vol. 22 n. 2, 2006. p. 201-210. Disponível em: <http://www.scielo.br/pdf/ptp/v22n2/a10v22n2>. Acesso em 12 JUN 2012.

MENDOZA, Héctor José García. Formação por etapas das ações mentais na atividade de situações problema em matemática. In: X ENCONTRO NACIONAL DE EDUCAÇÃO MATEMÁTICA, 2010, Salvador. Anais...Salvador: Sociedade Brasileira de Educação Matemática, 2010. p. 1-11. Disponível em:

<http://www.lematec.net.br/CDS/ENEM10/artigos/MR/MR12_Mendoza.pdf >. Acesso em 13 JUL 2012.

MENDOZA, Héctor José García; TINTORER, Oscar Delgado. Sistema de ações para melhorar o desempenho dos alunos na atividade de situações problema em matemática. In: XIII CONFERENCIA INTERAMERICANA DE EDUCACIÓN MATEMATICA, 2011, Recife. Anais... Recife: XIII CIAEM-IACME, 2011. p. 1-12. Disponível em: <https://w3.dmat.ufrr.br/hector/MetPesq2Ex04.pdf>. Acesso em 13 JUL 2012.

OLLAIK, Leila Giandoni; ZILLER, Henrique Moraes. Concepções de validade em pesquisas qualitativas. Scientiae Studia, Educação e Pesquisa, São Paulo, v. 38, n. 1, 2012. p. 229241. Disponível em: 〈http://www.scielo.br/pdf/ep/v38n1/ep448.pdf〉. Acesso em 1 FEV 2013.

RIBEIRO, Raimunda Porfírio. O processo de aprendizagem de professores do ensino fundamental: apropriação da habilidade de planejar situações de ensino de conceitos. 2008. 233f. Tese (Doutorado em Educação) - Universidade Federal do Rio Grande do Norte, Natal. Disponível em: <https://repositorio.ufrn.br/jspui/bitstream/123456789/14164/1/RaimundaPR.pdf>. Acesso em 23 JUN 2012.

TALÍZINA, Nina. Psicologia de La enseñanza. Moscú: Editorial Progresso, 1988. 


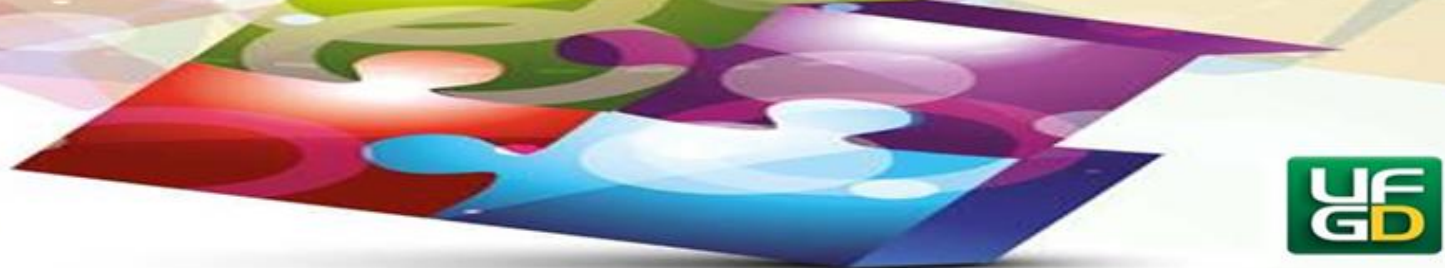

WITTMANN, Lauro Carlos; KLIPPEL, Sandra Regina. A prática da gestão democrática no ambiente escolar. - Curitiba: Ibpex, 2010.

Enviado: 06/06/2019

Aceito: 30/06/2019 